Curtin, L., Stephens, R.S., \& Bonenberger, J. (2001). Goal setting and feedback in the reduction of heavy drinking in female college students. Journal of College Student Psychotherapy, 15:3 pp. 17-37.

Haworth Press (now Taylor \& Francis) http://www.informaworld.com (ISSN: 8756-8225) Accepted

08/03/2000. DOI: 10.1300/J035v15n03_03

\title{
Goal Setting and Feedback in the Reduction Of Heavy Drinking in Female College Students
}

\author{
Lisa Curtin, Robert Stephens \& Jacob L. Bonenberger
}

\begin{abstract}
The present study examines self-regulation variables (goals, feedback, goal commitment, efficacy, discrepancy)within the context of a brief intervention designed to decrease heavy drinking amongst college females. Participants $(\mathrm{N}=76)$ were randomly assigned to one of six between subjects conditions created by crossing goal conditions (no goal, proximal goal, distal goal) with feedback conditions (feedback, no feedback), and were assessed across time on drinking behavior and self-regulation variables. Neither goal setting, feedback, nor the combination of goal setting and feedback were superior to assessment and information in the reduction of heavy drinking. The interaction of efficacy, commitment and discrepancy failed to add to the prediction of future drinking beyond that accounted for by current drinking behavior and the main effects of self-regulation variables in hierarchical regression analyses. Correlational analyses revealed a negative relationship between efficacy and commitment and future drinking behavior. Results are discussed in relation to theory, the college student environment, and the potential limited efficacy of individual level interventions within this environment.
\end{abstract}

Keywords: brief intervention | feedback | goal setting | self-regulation

\begin{abstract}
ARTICLE
College student drinking is a common phenomenon (Leavy\&Dunlosky, 1989; O'Hare, 1990), with rates generally between 80 and 90\% (Saltz\& Elandt, 1986). Not only do many college students consume alcohol, but heavy drinking within this population has been associated with a myriad of problems ranging from negative effects on academic performance to driving while intoxicated (Saltz \& Elandt, 1986; Wechsler \& Isaac, 1992). Consistent with these potential hazards, The Institute of Medicine (IOM; 1990) has noted the need to provide college students with services to prevent future drinking problems. Similarly, national goals for health promotion and disease prevention outlined in Healthy People 2000 (Department of Health and Human Services, 1991) include
\end{abstract}


reducing occasions of heavy drinking by young people and providing better access to treatment. The present study addresses these goals by investigating mechanisms that foster behavior change in a sample of heavy drinking college females.

Models of self-regulation have been proposed as a "context through which to understand, treat and prevent addictive behaviors" (Miller \& Brown, 1991, p. 60). Self-regulation is proposed to function via a feedback loop. When a person who is committed to a goal receives feedback that he/she is not achieving that goal, a discrepancy between the goal and the individual's behavior is activated. The discrepancy serves as an impetus for discrepancy reduction. According to Bandura (1986, 1991), the discrepancy will be reduced by increasing goal directed efforts if the individual has positive efficacy expectancies. The feedback loop can function in both a proactive and reactive manner. People create discrepancy through setting goals that are inconsistent with current behavior. People also act to decrease discrepancy when current behavior fails to match desired goal behavior.

Social-cognitive theory (Bandura, 1986) differentiates between proximal goals and distal goals. Distal goals are generally long-term and distant from current behavior. On the other hand, proximal goals are subgoals which are generally smaller and provide a more proximate comparative standard relative to distal goals. Laboratory task studies (Locke, Shaw, Saari \& Latham, 1981; Masters, Furman \& Barden, 1977) and field studies (Bandura \& Simon, 1977; Perri \& Richards, 1977) have found that goals result in better performance when they are proximal, explicit and challenging rather than when they are distal, vague and easy.

Although goals are considered motivational in and of themselves, there is ample evidence for the effect of feedback on the propensity of goals to motivate behavior (Bandura \& Cervone, 1983; Becker, 1978; Erez, 1977). Feedback is proposed to provide information concerning goal-related performance (e.g., positive feedback as reinforcement) and to serve as a sign of progress which can affect motivation through self-evaluative mechanisms (Bandura, 1986). Self-efficacy is defined as "people's judgments of their capabilities to organize and execute courses of action required to attain designated types of performances" (Bandura, 1986, p. 391). According to Bandura (1986) self-efficacy partially determines whether a discrepancy between a goal standard and current behavior will be discouraging or motivating. Discrepancy in the face of low efficacy is predicted to lead to decreased persistence toward the standard whereas high efficacy will promote increased persistence toward the standard (Bandura \& Cervone, 1986).

Although goals, feedback and self-efficacy provide promise for maintaining goal-congruent persistence, commitment is theoretically 
considered a prerequisite to the effectiveness of goal setting (Locke, Latham \& Erez, 1988). There is some evidence of a positive relationship between commitment and laboratory task performance (Locke \& Shaw, 1984), and the substance abuse literature lends indirect support to the relationship between commitment and positive outcome. Commitment to an abstinent goal at the end of treatment for alcohol, opiate or nicotine abuse significantly related to a decreased risk of a slip for the next 12 weeks (Hall, Havassy \& Wasserman, 1990), and the same relationship was found in a sample of cocaine patients (Hall, Havassy \& Wasserman, 1991). However, the majority of empirical investigations of the effectiveness of goal setting fail to measure commitment (Hollenbeck \& Klein, 1987).

Self-regulation models have been discussed in terms of substance abuse etiology and treatment (Miller \& Brown 1991); however, the individual and interactive functions of self-regulation variables have undergone limited systematic investigation. Both behavioral self-control training (Harris \& Miller, 1990) and brief assessment and feedback interventions (Miller \& Rollnick, 1991; Bien, Miller, \& Tonigan, 1993) employ goal setting and have resulted in encouraging findings. Despite the central role assigned to goals, feedback, and discrepancy production, tests of self-regulation based interventions have not assessed and evaluated their impact on the presumed mediating variables. Research examining the hypothesized roles of self-regulatory variables is needed to understand how current treatment programs work, design more effective treatment programs, and evaluate theory in the area of behavior change.

The present study used a brief intervention to examine the effectiveness of self-regulation variables in the reduction of heavy drinking occasions in college females. Epidemiological data indicates that despite stability in the overall percentage of women who report consuming alcohol, the makeup of that figure includes an increase in the percentage of younger female drinkers (Fillmore, 1987), and the gap between male and female college students' drinking practices has narrowed since the late 1970's (Mercer \& Khavari, 1990) revealing nearly identical percentages of drinkers and abstainers (Johnson, O’Malley \& Bachman, 1989). There is a call for investigation of women's drinking and treatment (Gomberg, 1993), and some studies, although not all (Baer et al., 1992), have found females to benefit significantly more than males in self-help/brief intervention formats (Robertson, Heather, Dzialdowski, Crawford \& Winton, 1986; Sanchez-Craig, Davila, \& Cooper, 1996; Sanchez-Craig, Leigh, Spivak \& Lei, 1989).

Within the context of a brief intervention, the individual impact of goal setting, feedback, and goal setting combined with feedback, as well as their interaction with other self-regulatory variables (efficacy, commitment and discrepancy) were examined. Three levels of goals (no goal, proximal goal, and distal goal) for reduction in heavy drinking 
occasions were manipulated and crossed with two levels of feedback (no feedback, feedback). Theoretically important self-regulatory variables as well as drinking behavior were measured across time.

Participants assigned to the proximal goal condition were expected to achieve the greatest reduction in heavy drinking, followed by participants in the distal goal condition, and finally by participants in the no goal condition. The provision of feedback was predicted to produce greater behavior change in combination with the proximal and distal goal conditions compared to the no goal condition. Finally, the interaction of efficacy, commitment and discrepancy was expected to significantly add to the prediction of future drinking beyond that predicted by the main effects of the individual self-regulation variables and current drinking behavior. Future behavior change was hypothesized to be greatest when all components of self-regulation were present.

\section{METHOD}

\section{Participants}

One hundred forty volunteer female undergraduate students were screened. Eligibility criteria included: (1) a minimum of four heavy drinking occasions during the past month. Frequency of heavy drinking occasions was defined as the number of times the individual reached an estimated Blood Alcohol Concentration (BAC) of .08\% or above based on number of self-reported, standard alcoholic drinks, time period of consumption and body weight; (2) a minimum of one alcohol-related problem in the past six months on the Rutgers Alcohol Problem Index (RAPI; White \& Labouvie, 1989); (3) no health-related contraindications to alcohol consumption (i.e., medication, pregnancy); (4) not currently participating in any type of alcohol intervention; (5) willingness to identify a collateral to independently report on the participant's drinking at the one and two month follow-ups. Of the 140 screened participants, 81 participants $(58 \%)$ were eligible. All ineligible participants $(n=59)$ reported fewer than the minimum number of four heavy drinking occasions during the past month. Five of the eligible participants chose not to participate due to scheduling difficulties $(n=3)$ and/or lack of interest $(n=2)$.

The final set of participants were 76 female university students. Participants' mean age was $19.51(S D=1.26)$ years and all were single. The majority were Caucasian $(94.7 \%)$, and nearly equal percentages of participants lived on campus (52.6\%) as off campus (47.4\%). Thirty-four percent of participants were members of a sorority, and 5.3\% were little sisters for a fraternity. Participants reported experiencing an average of $14.47(S D=6.63)$ alcohol-related problems across the past six months. Across the preceding month, participants reported an average of 9.75 $(S D=3.69)$ occasions of drinking of which $7.40(S D=3.26)$ were heavy 
drinking occasions. Cumulatively, across these 9.75 occasions, participants consumed an average of $68.46(S D=51.41)$ standard drinks, or $6.56(S D=2.43)$ standard drinks per occasion of drinking, representing an average estimated BAC of $.17(S D=.07)$.

\section{Measures}

The Time-Line Follow-Back method (TLFB; Sobell, Sobell, Klajner, Pavan \& Basian, 1986) was utilized to assess daily quantity and frequency of alcohol consumption and patterns of alcohol consumption at all assessment points. This method uses a calendar with self-generated memory anchor points (e.g., holidays, parties) to assist the participant in reconstructing daily alcohol consumption. The present study assessed alcohol consumption for the preceding month based on the recommendations of Sobell et al. (1986) regarding adequate test-retest reliability across a 30-day time period with college students ( $r$ 's ranging from .76 to .96). Participants were provided with a calendar of the previous month, and asked to provide daily reports of the type and amount of alcohol consumed and the number of hours over which drinking occurred. Total number of standard drinks consumed across the past month was divided by the number of times the participant reported drinking any alcohol to create a variable representing the average number of alcoholic beverage consumed per occasion (average quantity).

A computer program, Blood Alcohol Concentration Calculation System (BACCUS), developed by Markham and Miller (1991) was used in combination with body weight to compute BAC estimates for each drinking episode reported on the TLFB. The primary dependent variable represents the frequency of times a participant BAC reached an estimated $.08 \%$ or greater (heavy drinking occasions).

Efficacy was assessed using the Alcohol Coping Efficacy Scale (ACES; Greaves, Stephens \& Curtin, 1992). The coping efficacy measure consisted of 18 items corresponding to specific behavioral skills for avoidance of heavy drinking, such as taking slow sips on a drink, refusing unwanted drinks or keeping track of the number of drinks consumed.

Subjects rated their confidence in their ability to utilize each coping skill on a scale ranging from 0 "not at all confident" to 100 "very confident." Total scores represent an average across coping skills efficacy ratings. Principle components analysis indicated a unidimensional structure, and reliability analyses showed good internal consistency (alpha $=.97$ ).

Commitment to assigned goals was assessed using the question, "I am strongly committed to not drinking heavily," an item adapted from academic goal setting research (Hollenbeck, Williams \& Klein, 1989). Participants were asked to respond true or false to the question; a true response was assigned one point whereas a false response was assigned 
zero points. Finally, participants were asked to respond to the question "How large is the difference between your current drinking and your goal concerning heavy drinking?" on a scale ranging from 1 "not at all different" to 7 "very different." This was utilized as an indication of subjective discrepancy between current drinking and desired drinking.

\section{Collateral Reports}

To assess the reliability of participant self-reports of drinking, estimates of participant drinking were obtained from collateral reporters at the one month and two month follow-ups. Collateral reporters estimated the number of days the participant used any alcohol at all, the number of alcoholic drinks she typically consumed when drinking, and how much alcohol she consumed in an average week during the past 30 days. Collateral responses were correlated with estimates from the participants' own reports on the TLFB corresponding to the same time period. Sixty-seven percent of collateral reporters $(n=51)$ participated in the one month follow-up, and $80 \%$ of collateral reporters $(n=61)$ participated in the two month follow-up. Correlations between subjects' and collaterals' reports at the one month follow-up yielded the following relationships: average number of drinks per week $r=.60, p<.001$ ), average number of drinks per occasion $r=.46, p<.001$ ) and number of drinking days $r=.48, p<.001)$. Correlations computed at the two month follow-up were as follows: average number drinks per week $r=$ $.44, p<.001$ ), average number of drinks per occasion $r=.39, p<.001$ ) and number of drinking days $r=.38, p<.002$ ). Participants systematically underreported their alcohol consumption on all variables compared to collaterals (all $p$ 's $<.05$ ).

\section{Design}

The overall design was a 3 (goal: no goal, proximal goal, distal goal) 2 (feedback: feedback versus no feedback) _ 3 (time: initial session, 1 month, 2 months) mixed-model factorial design. Goal condition and feedback condition served as between subjects factors. Time served as a within subjects factor. Participants were randomly assigned to one of the six between subjects conditions created by crossing the three goal conditions with the two feedback conditions. Thirteen participants were randomly assigned to each of the following conditions: no goal/no feedback, no goal/feedback, proximal goal/no feedback, and proximal goal/feedback conditions. Twelve participants were randomly assigned to the distal goal/no feedback and the distal goal/feedback conditions.

\section{Procedure}

Recruitment and Screening. Recruitment strategies included the psychology department subject pool; flyers posted around campus, at the counseling/health center and in the Greek organizations; and newspaper 
ads. These promoted a brief program for females 18 and older who were interested in learning about their drinking behavior and/or changing their drinking patterns. Interested individuals were instructed to contact the investigator for information concerning participation and were then scheduled for a group screening. Following written informed consent, a general demographic information questionnaire, a health screening questionnaire, the TLFB and the RAPI were administered.

Initial Intervention Procedure. Participants meeting inclusion criteria were invited to an individual assessment and brief intervention session lasting approximately one hour. Interested participants were asked to identify a friend familiar with her drinking habits who would be willing to provide a report of the participant's drinking. The participant was instructed to bring her friend's name, address and phone number to the first scheduled session. Consent forms and self-addressed stamped return envelopes were mailed to collateral informants assuring them that their responses were confidential and would not be shared with the participant.

Individual assessment and feedback sessions were conducted by one of two female clinical psychology Ph.D. candidates. Participants first granted the researcher written informed consent, and then completed the TLFB and ACES. After completing measures, participants were randomly assigned to receive one of three goal assignments: no goal, proximal goal, or distal goal. Within each of these three goal conditions participants were randomly assigned to one of two feedback conditions: feedback or no feedback.

Goal Conditions. After completing the TLFB and ACES, participants assigned to the no goal condition received a list of cognitive and behavioral strategies for avoiding heavy drinking as well as BAC tables to estimate BAC levels from weight and number of alcoholic drinks consumed. This information was presented to participants with the explanation that other college students reported finding such information and strategies helpful in controlling heavy drinking.

Participants in the proximal goal condition were provided with the same drinking control information and rationale provided to no goal participants. The value of goal setting for directing attention, increasing persistence and resulting in greater behavior change was explained to participants. It was recommended that they utilize this information while attempting to reduce their number of heavy drinking occasions by $50 \%$ during the upcoming month. Goals were individually defined based on baseline frequency of heavy drinking occasions. Participants were provided with a written goal specifying the maximum number of times they were to drink the number of drinks necessary to reach a BAC of $.08 \%$ during a four hour time period. During the one month reassessment, participants who were able to achieve their $50 \%$ reduction goal were instructed to reduce their number of heavy drinking occasions by $75 \%$ compared to baseline levels. Participants who were unable to 
achieve their $50 \%$ reduction goal were instructed to continue attempts to meet the $50 \%$ reduction goal. All participants were able to discuss successes and difficulties in meeting their goal with the therapist.

Participants in the distal goal condition also received the drinking control information and rationale. They were then instructed verbally and in writing to use these to reduce their number of heavy drinking occasions by $75 \%$ over the next two months. Again, the value of goal setting was shared with participants, and during the one month follow-up participants were able to discuss goal-related successes and difficulties with the experimenter.

Feedback. Half of the participants in each of the three goal conditions were randomly assigned to receive written and verbal feedback during both the initial intervention session and the one month follow-up session. Feedback concerned weekly average quantity of alcohol consumption, average quantity of alcoholic beverages consumed per occasion, average number of heavy drinking days during the past month and highest BAC level during the past month. In the proximal and distal goal conditions feedback was delivered in relation to the specified goal. Feedback in the no goal condition provided participants with a description of their drinking behavior without any reference to a goal standard.

After the goal and feedback manipulation, participants completed questions assessing goal commitment and subjective discrepancy. Finally, participants were scheduled for reassessment appointments one and two months later.

Reassessment Procedures. Ninety-seven percent $(n=74)$ of participants completed the one month reassessment and ninety-one percent $(n=69)$ completed the two month reassessment. Eighty-nine percent $(n=68)$ of participants completed all three assessments.1 At the one-month followup, participants first completed the TLFB and ACES. Participants assigned to receive feedback were then provided with drinking feedback based on the current drinking assessment. This feedback was delivered in relation to goal progress for participants in the proximal and distal goal conditions. Participants in the distal goal condition were reminded of their goal. Participants in the proximal goal condition were either offered a recommended goal change (from 50\% reduction to $75 \%$ reduction), or encouraged to continue working on the original goal (50\% reduction from baseline) if that goal had not been reached. Participants then completed questions assessing commitment and discrepancy.

Two month follow-up assessment sessions were conducted in small groups of 5 to 10 as no individualized feedback or instruction was required. The two month follow-up included the TLFB and a brief questionnaire concerning perception of goal assignment, and participation in alcohol or psychological intervention(s) while participating in the study. 


\section{RESULTS}

\section{Goal Attainment}

Fifty of the 76 participants were assigned a goal. Of these 50 participants, 49 completed the one month follow-up. Thirteen (27\%) of the 49 participants met the assigned goal ( 8 proximal goals, 5 distal goals) and $36(73 \%)$ did not meet the assigned goal. Of the 13 participants who met the assigned goal at the one month follow-up, only six maintained this at the two month follow-up (4 proximal goals, 2 distal goals). Of the 36 participants who had not met the goal at the one month follow-up, five met the goal at the two month follow-up (2 proximal goals, 3 distal goals).

Hypotheses one and two were addressed simultaneously. Outcome as a function of goal condition, feedback condition, and their interaction was tested using a MANOVA approach to repeated measures with goal assignment (no goal, proximal goal, distal goal) and feedback (feedback, no feedback) as the between subjects factors, and time (initial, 1 month, 2 months) as the within subjects factor. A goal_feedback_time interaction with greatest reduction occurring in the proximal goal condition, followed by the distal goal condition, and finally the no goal condition would support hypothesis one. In addition, hypothesis two would be supported if reduction was greater in each of the goal conditions with the addition of feedback. Separate analyses were conducted for the two dependent variables of frequency of heavy drinking occasions and average quantity per occasion (see Table 1 for means and standard deviations).

A MANOVA using the $\log _{2}$ of the number of heavy drinking occasions at the initial session, one month follow-up, and two-month followup as dependent variables revealed a main effect of time (Pillai's 
TABLE 1. Frequency of Heavy Drinking Occasions and Average Quantity as a Function of Feedback and Goal Conditions Across Time

\begin{tabular}{|c|c|c|c|c|c|}
\hline & & & $\underline{\text { Initial }}$ & One Month & Two Months \\
\hline \multirow[t]{6}{*}{ Feedback } & \multirow[t]{2}{*}{ No Goal } & Heavy Drinking & $6.95(2.91)$ & $4.25(3.65)$ & $4.58(2.43)$ \\
\hline & & Average Quantity & $5.99(1.89)$ & $5.11(2.11)$ & $5.17(1.90)$ \\
\hline & \multirow[t]{2}{*}{ Proximal Goal } & Heavy Drinking & $8.25(5.53)$ & $9.33(5.31)$ & $8.58(5.38)$ \\
\hline & & Average Quantity & $7.83(2.68)$ & $6.49(2.74)$ & $7.39(2.38)$ \\
\hline & \multirow[t]{2}{*}{ Distal Goal } & Heavy Drinking & $6.82(1.99)$ & $3.91(2.43)$ & $3.82(2.60)$ \\
\hline & & Average Quantity & $6.48(2.38)$ & $4.95(2.08)$ & $4.86(1.81)$ \\
\hline \multirow[t]{6}{*}{ No Feedback } & \multirow[t]{2}{*}{ No Goal } & Heavy Drinking & $7.36(2.94)$ & $6.27(4.29)$ & $5.73(3.04)$ \\
\hline & & Average Quantity & $5.93(1.74)$ & $5.10(1.73)$ & $5.55(1.50)$ \\
\hline & \multirow[t]{2}{*}{ Proximal Goal } & Heavy Drinking & $7.18(2.60)$ & $4.09(2.84)$ & $3.91(2.30)$ \\
\hline & & Average Quantity & $6.87(2.13)$ & $4.16(1.32)$ & $4.37(1.30)$ \\
\hline & \multirow[t]{2}{*}{ Distal Goal } & Heavy Drinking & $6.84(2.01)$ & $4.36(2.80)$ & $5.09(2.88)$ \\
\hline & & Average Quantity & $6.25(2.22)$ & $5.04(2.18)$ & $5.06(1.70)$ \\
\hline \multirow[t]{2}{*}{ Entire Sample } & & Heavy Drinking & $7.38(3.27)$ & $5.41(2.88)$ & $5.32(3.59)$ \\
\hline & & Average Quantity & $6.49(2.22)$ & $5.16(2.13)$ & $5.43(2.00)$ \\
\hline
\end{tabular}

statistic $=.46$, approximate $F(2,58)=24.77, p<.01)$. Repeated measures ANOVA's indicated a significant difference between frequency of heavy drinking occasions at the initial session and one month followup $(F(1,58)=33.21, p<.001)$, and between the initial session and two month follow-up $(F(1,58)=47.39, p<.001)$. A significant difference was not found between the one month and two month follow-ups $(F(1,58)=0.01, p>.05)$. No multivariate interaction effects were found.

An identical MANOVA was conducted utilizing average number of drinks per occasion as the dependent variable. Similarly, a significant multivariate effect of time emerged (Pillai's statistic $=.39$, approximate $F(2,61)=19.44, p<.001)$. A significant reduction in average number of drinks consumed was noted between the initial assessment and the one month follow-up $(F(1,62)=36.03, p<.001)$, and between the initial assessment and the two month follow-up $(F(1,62)=21.48, p<$ $.001)$. No differences were found between average quantity per occasion consumed at the one month and the two month follow-ups ( $F(1$, $62)=1.31, p>.05)$. Again, no multivariate interaction effects were found.

\section{Prediction of Future Drinking}

Hypothesis three concerned the prediction of future drinking as a function of self-regulation variables. Thiswas assessed utilizing correlational and multiple regression analyses. Correlations were computed between 
baseline drinking variables and self-regulation variables and the drinking outcomes at the one month follow-up. These analyses were repeated for drinking and self-regulation variables measured at one month, and the two month drinking outcomes (see Table 2 for zero-order correlations $(r$ 's) between self-regulation variables and future drinking behavior).

Drinking behavior was most highly correlated with drinking behavior one month later. Consistent with theory, confidence in ability to uti-

TABLE 2. Zero-Order Correlations Between Self-Regulation Variables and Future Drinking Behavior

\begin{tabular}{|c|c|c|c|c|}
\hline & \multicolumn{2}{|c|}{$\begin{array}{c}\text { Baseline Self-Regulation Variables } \\
\text { and One Month Drinking }\end{array}$} & \multicolumn{2}{|c|}{$\begin{array}{l}\text { One Month Self-Regulation } \\
\text { Variables and Two Month Drinking }\end{array}$} \\
\hline & $\begin{array}{l}\text { Heavy Drinking } \\
\text { Occasions }\end{array}$ & $\begin{array}{l}\text { Average } \\
\text { Quantity }\end{array}$ & $\begin{array}{l}\text { Heavy Drinking } \\
\text { Occasions }\end{array}$ & $\begin{array}{l}\text { Average } \\
\text { Quantity }\end{array}$ \\
\hline Heavy Drinking & $.70^{\mathrm{xxx}}$ & - & $.58^{1 \times x}$ & - \\
\hline Average Quantity & - & $.63^{\mathrm{xx}}$ & - & $.61^{\mathrm{xx}}$ \\
\hline Coping Efficacy & $-.57^{\mathrm{mx}}$ & $-34^{\mathrm{xx}}$ & $-36^{*}$ & -.16 \\
\hline Commitment & $-.53^{\mathrm{mx}}$ & $-.44^{m x}$ & $-.27=$ & $-36^{m x}$ \\
\hline Discrepancy & .13 & $.28^{\mathrm{xx}}$ & $.25^{*}$ & .15 \\
\hline
\end{tabular}

lize various coping strategies to avoid drinking heavily, and commitment to not drinking heavily was negatively associated with future drinking. Subjective discrepancy between actual drinking behavior and heavy drinking goal revealed a positive, although not consistently significant, correlation with drinking one month later.

Hierarchical regression analyses were conducted to predict future number of heavy drinking occasions and average quantity per occasion from the self-regulation variables of efficacy, commitment and subjective discrepancy. It was hypothesized that the interaction of greater efficacy, commitment and discrepancy would significantly add to the prediction of future drinking beyond that accounted for by both present behavior and these variables individually. Variables were entered into a hierarchical regression equation in steps in the following order: (a) current drinking variable to control for behavior at the time of assessment (b) main effects of efficacy, commitment and discrepancy (c) interaction of efficacy, commitment and discrepancy created by computing a product of the z-scores of the three.

Frequency of heavy drinking occasions at baseline accounted for 
$49 \%$ of the variance in the frequency of heavy drinking occasions at one month $(F(1,72)=68.87, p<.001)$. As a block, the main effects of efficacy, commitment and discrepancy entered the equation and accounted for an additional $13 \%$ of the variance in frequency of heavy drinking occasions one month later $(F(3,69)=7.82, p<.001)$. Contrary to prediction, the interaction of the self-regulation variables of coping efficacy, commitment and discrepancy failed to enter the model and add to the prediction of future heavy drinking $(p>.05)$. The same analysis was repeated for the prediction of drinking at two months from data collected at one month. Frequency of heavy drinking at one month accounted for $34 \%$ of the variance $(F(1,65)=35.94, p<.001)$. Neither the main effects nor the interaction of self-regulation variables added to the prediction of frequency of heavy drinking occasions at the two month followup (all $p$ 's > .05).

Identical regression analyses were conducted to predict average number of alcoholic beverages per occasion at both the one month and the two month follow-up. Average quantity per occasion assessed at baseline accounted for $40 \%$ of the variance in average quantity per occasion reported at the one month follow-up $(F(1,72)=48.10, p<.001)$.

The main effects of efficacy, commitment and discrepancy, and their interaction failed to significantly add to the prediction of average quantity per occasion one month later (all $p$ 's > .05). An identical regression analysis was conducted to predict average quantity per occasion reported at two months from average quantity per occasion and self-regulation variables measured at the one month assessment. Similarly, average quantity at one month accounted for $37 \%$ of the variance in average quantity reported at two months $(F(1,65)=37.80, p<.001)$. Again, self-regulation variables of efficacy, commitment and discrepancy, and their interaction, failed to account for significant variance in the average quantity at the two month follow-up.

\section{DISCUSSION}

The present study tested self-regulatory principles (Bandura, 1986) within the context of a brief intervention (Bien et al., 1993) designed to reduce heavy drinking in college females. Contrary to hypotheses, the present study did not find goal setting, the provision of feedback, or the combination of goal setting and feedback to be superior to assessment and information in the reduction of heavy drinking. As predicted, the self-regulation variables of efficacy and commitment did relate negatively to future drinking behavior in univariate correlational analyses. However, the interaction of efficacy, commitment and discrepancy failed to add to the prediction of future drinking beyond that accounted for by current drinking behavior and the main effects of these self-regulation variables in hierarchical regression analyses.

Although the overall change across time of brief interventions in the 
present study is comparable to other college student interventions (Baer et al., 1992), the failure of goal setting and feedback delivery to enhance change is counter to theory (Bandura, 1986; Locke et al., 1981; Miller \& Rollnick, 1991) and past findings (Bandura \& Schunk, 1981; Bandura \& Simon, 1977). Goals assigned in the present study were individualized and explicitly presented verbally and in writing. It is possible that the limited incremental increases in the proximal goal condition (from 50\% to $75 \%$ reduction in frequency of heavy drinking occasions) compromised the true proximal nature of the goal setting procedure, and, in turn, limited the propensity of the proximal goal to increase goal congruent behavior. Baumeister, Heatherton and Tice (1994) suggest that a combination of both proximal and distal goals may be most helpful in self-regulation efforts. This combination may provide for increases in self-efficacy as a result of proximal success experiences (Bandura \& Schunk, 1981), and continual motivation as a result of the long-term distal goals.

Choice or participation in goal setting may also have limited the impact of goal setting. In an effort to preserve the internal validity of the present study, goals were assigned and not collaborative. Although the literature on goal setting does not clearly support an advantage of participative goals relative to assigned goals (Locke et al., 1981), some studies have noted a positive relationship between goal-related performance and participative goals (Erez \& Arad, 1986). Perhaps, however, the absence of a goal setting effect lies in the value participants placed on the assigned goal. In a college environment, in which drinking is considered acceptable and common (Baer, 1993; O'Hare, 1990), future drinking reduction may not be valued. Both social and personal comparisons can act as standards that are utilized in the personal judgment of behavior necessary for self-regulation (Bandura, 1986). Not only does an individual engage in evaluation of her behavior relative to her own standards/goals, but also in relation to social comparisons (Baer, Stacy, \& Larimer, 1991). Social comparisons in a college environment likely support the acceptability of heavy drinking rather than drinking reduction and selectivity of peers and peer modeling may attenuate the success of an individual level intervention (Baer et al., 1993; Kivlahan, Marlatt, Fromme, Coppel, \& Williams, 1990).

Further, in the context of college student drinking not only may a drinking reduction goal be devalued, but there is likely competing feedback. Environmental feedback from peers and the college environment may support heavy drinking rather than drinking reduction and such feedback occurs more frequently than intervention provided feedback. Perri and Richards' (1977) investigation of naturally occurring self-control in college students found that positive reinforcement from external sources (e.g., friends, parents) distinguished those who were successful in efforts toward self-regulation from those who were not successful. It is possible that feedback from peers punished participants' attempts to reduce heavy drinking rather than reinforced such attempts. 
The study procedure may also have limited the effect of the feedback manipulation. All participants were assessed at screening, the initial session, one month assessment and two month assessment. Many participants noted "paying attention" to her drinking to help with anticipated retrospective reporting. Thus, it is possible that the reduction noted in the present study was influenced by assessment or self-monitoring of drinking behavior (Bandura, 1986; Baumeister et al., 1994). Unfortunately, the absence of a wait list control group in the present study precludes examination of an assessment or monitoring effect.

In addition to testing the impact of goal setting and feedback on reduction in heavy drinking, the present study also tested the utility of additional self-regulation variables in predicting future drinking behavior. Regression analyses were conducted to predict frequency of heavy drinking and future average quantity one month later from the main effects and interaction of the self-regulation variables of efficacy, commitment and discrepancy. In all cases current drinking behavior accounted for the greatest amount of variance in future drinking behavior. Only in the prediction of frequency of heavy drinking occasions at the one month assessment did the main effects of the self-regulation variables enter the regression equation. Further, contrary to hypotheses, the interaction of efficacy, commitment and discrepancy consistently failed to add to the prediction of future drinking behavior. Theoretically (Bandura, 1986), drinking reduction should be greatest with the combination of subjective discrepancy between current drinking and desired drinking patterns, and high levels of efficacy for and commitment to not drinking heavily. Both the measurement of commitment and discrepancy were exploratory in the present study and may have limited predictive utility. In addition, the same personal and contextual variables discussed as limitations for detecting goal and feedback effects may equally limit the predictive usefulness of the self-regulation variables of efficacy, commitment and discrepancy.

The present study provides some insight into the utility and the limitations of self-regulation interventions in the reduction of heavy drinking in college women. However, some caution should be exercised when considering the results. The lack of a wait list control group makes it impossible to know whether drinking reductions reflect the assessment, experiment contact and/or information, or a natural history or selection factor. Measures of commitment and discrepancy were exploratory and thus potentially limited in terms of their predictive utility. In addition, although the relationship between collateral reports and self-reports were consistently and significantly positively correlated, the relationships were not very strong. Further, collateral informants consistently reported more drinking on the part of the participant compared to participant self-reports. This is consonant with findings that college students maintain an overreporting bias when assessing the drinking habits of their peers (Baer et al., 1991). Such a bias may contribute to perceptions of the environment as endorsing heavy drinking 
more so than the actual environment endorses heavy drinking. It is also likely that college student collaterals have less contact (Babor, Stephens, \& Marlatt, 1987) with participants compared to clinical samples.

It is suggested that adjunct interventions such as daily self-monitoring be considered in an effort to increase the effect size of similar interventions. For example, daily self-monitoring of drinking behavior rather than periodic assessments may serve to increase awareness across time. In addition, frequent contacts from experimenters may also serve to prompt self-awareness, behavior change or goal adherence (Lombard, Lombard \& Winett, 1995; McConnell, Biglan \& Severson, 1984). In fact, research in the exercise adherence literature (Lombard et al., 1995) suggests that frequent "touching base" (pg. 164) prompts may be as effective as prompts incorporating goal setting and feedback. Community-level interventions likely hold greater promise in reducing heavy college student drinking compared to individual level interventions. As discussed, the college environment and acceptability of heavy drinking may limit the impact of individual level interventions. Interventions delivered to large cohorts, especially if delivered by peer models (Bandura, 1986; Rogers, 1983), may function to alter normative attitudes and the everyday environment in relation to heavy drinking.

\section{NOTES}

1. The 68 participants who completed all assessments did not differ significantly from the eight participants with incomplete data on pretreatment number of heavy drinking occasions, $F(1,74)=1.89, p>.05$; average BAC, $F(1,74)=1.02, p>.05$; average quantity per occasion, $F(1,74)=0.63, p>.05$; or frequency of drinking occasions, $F(1,74)=1.90, p>.05$.

2. Evaluation of the skewness (2.00) and kurtosis (5.85) of the distribution of heavy drinking occasions at baseline suggests deviation from normality. Based upon the recommendation of Stevens (1992) as well as Tabachnick and Fidel (1989), the frequency of heavy drinking occasions was logarithmically transformed. Logarithmic transformations were unable to be computed for three of the 68 total participants due to their having zero heavy drinking occasions at one of the follow-up assessments.

\section{REFERENCES}

Babor, T. S., Stephens, R.S., \& Marlatt, G.A. (1987). Verbal report methods in clinical research on alcoholism: Response bias and its minimization. Journal of Studies on Alcohol, 48, 410-424.

Baer, J.S. (1993). Etiology and secondary prevention of alcohol problems with young adults. In J.S. Baer, G.A. Marlatt, \& R.J. McMahon (Eds.) Addictive Behaviors Across the Life Span. Newbury Park, CA: Sage.

Baer, J.S., Marlatt, G.A., Kivlahan, D.R., Fromme, K., Larimer, M.E., \& Williams, E. (1992). An experimental test of three methods of alcohol risk reduction with young adults. Journal of Consulting and Clinical Psychology, 60, 974-979.

Baer, J.S., Stacy, A.,\&Larimer,M. (1991). Biases in the perception of drinking norms 
among college students. Journal of Studies on Alcohol, 52, 580-586

Bandura, A. (1986). Social foundations of thought and action: A social cognitive theory. New Jersey: Prentice-Hall.

Bandura, A. (1991). Social cognitive theory of self-regulation. Organizational Behavior and Human Decision Processes, 50, 248-287.

Bandura, A., \& Cervone, D. (1983). Self-evaluative and self-efficacy mechanisms governing the motivational effects of goal systems. Journal of Personality and Social Psychology, 45, 1017-1028.

Bandura, A., \& Cervone, D. (1986). Differential engagement of self-reactive influences in cognitive motivation. Organizational Behavior and Human Decision Processes, $38,92-113$.

Bandura, A., \& Schunk, D.H. (1981). Cultivating competence, self-efficacy, and intrinsic interest through proximal self-motivation. Journal of Personality and Social Psychology, 41, 586-598.

Bandura, A., \& Simon, K.M. (1977). The role of proximal intentions in self-regulation of refractory behavior. Cognitive Therapy and Research, 1, 177-193.

Baumeister, R.F., Heatherton, T.F., \& Tice, D.M. (1994). Losing Control: How and why people fail at self-regulation. San Diego, CA: Academic Press, Inc.

Becker, L.J. (1978). Joint effect of feedback and goal setting on performance:Afield study of residential energy conservation. Journal of Applied Psychology, 63, 428-433.

Bien, T.H., Miller, W.R., \& Tonigan, J.S. (1993). Brief interventions for alcohol problems: A review. Addiction, 88, 315-336.

Erez,M. (1977). Feedback: A necessary condition for the goal setting-performance relationship. Journal of Applied Psychology, 62, 624-627.

Erez, M., \& Arad, (1986). Participative goal setting: Social, motivational, and cognitive factors. Journal of Applied Psychology, 71, 591-597.

Fillmore, K.M. (1987). Women's drinking across the adult life course as compared to men's. British Journal of Addiction, 82, 801-811.

Gomberg, E.S.L. (1993). Women and alcohol: Use and abuse. The Journal of Nervous and Mental Disease, 181, 211-219.

Greaves, C.K., Stephens, R.S., \& Curtin, L. (1992, November). The relative utility of alcohol expectancies and coping-efficacy in the prediction of drinking behavior. Paper presented at the meeting of the Association for the Advancement of Behavior Therapy, Boston, MA.

Hall, S.M., Havassy, B.E.,\& Wasserman, D.A. (1990). Commitment to abstinence and acute stress in relapse to alcohol, opiates, and nicotine. Journal of Consulting and Clinical Psychology, 58, 175-181.

Hall, S.M., Havassy, B.E., \& Wasserman, D.A. (1991). Effects of commitment to abstinence, positive moods, stress, and coping on relapse to cocaine use. Journal of Consulting and Clinical Psychology, 59, 526-532.

Harris, K.B., \& Miller, W.R. (1990). Behavioral self-control training for problem drinkers: Components of efficacy. Psychology of Addictive Behaviors, 4, 82-90. 
Hollenbeck, J.R.,\& Klein, H.J. (1987). Goal commitment and the goal setting process: Problems, prospects, and proposals for future research. Journal of Applied Psychology, $72,212-220$

Hollenbeck, J.R., Williams, C.R., \& Klein, H.J. (1989). An empirical examination of the antecedents of commitment to difficult goals. Journal of Applied Psychology, $74,18-23$.

Institute of Medicine (1990). Broadening the base of treatment for alcohol problems. Washington, DC: National Academy Press.

Johnson, L.D., O’Malley, P.M., \& Bachman, J.G. (1989). Drug use, drinking, and smoking: National survey results from high school, college, and young adult populations, 1975-1988. (DHHS Publication No. ADM 89-1638). Rockville, MD: National Institute on Drug Abuse.

Kivlahan, D.R., Marlatt, G.A., Fromme, K., Coppel, D.B.,\&Williams, E. (1990). Secondary prevention with college drinkers: Evaluation of an alcohol skills training program. Journal of Consulting and Clinical Psychology, 58, 805-810.

Leavy, R.L., \& Dunlosky, J.T. (1989). Undergraduate student and faculty perceptions of problem drinking. Journal of Studies on Alcohol, 50, 101-107.

Locke, E.A., Latham, G.D.,\&Erez,M. (1988). The determinants of goal commitment. Academy of Management Review, 13, 23-39.

Locke, E.A.,\&Shaw, K.N. (1984). Atkinson's inverse-U curve and the missing cognitive variables. Psychological Reports, 55, 403-412.

Locke, E.A., Shaw, K.N., Saari, L.M., \& Latham, G.P. (1981). Goal setting and task performance: 1969-1980. Psychological Bulletin, 90, 125-152.

Lombard, D.N., Lombard, T.N., \& Winett, R.A. (1995). Walking to meet health guidelines: The effect of prompting frequency and prompt structure. Health Psychology, 14, 164-170.

Markham, M.R., \& Miller, W.R. (1991). Blood Alcohol Concentration Calculation System (BACCUS) [Computer software]. University of New Mexico.

Masters, J.C., Furman, W., \& Barden, R.D. (1977). Effects of achievement standards, tangible rewards, and self-dispensed achievement evaluations on children's task mastery. Child Development, 48, 217-224.

McConnell, S., Biglan, A., \& Severson, H.H. (1984). Adolescents, compliance with self-monitoring and physiological assessment of smoking in natural environments. Journal of Behavioral Medicine, 7, 115-122.

Mercer, P.W., \& Khavari, K.A. (1990). Are women drinking more like men? An empirical examination of the convergence hypothesis. Alcoholism: Clinical and Experimental Research, 14, 461-466.

Miller, W.R., \& Brown, J.M. (1991). Self-regulation as a conceptual basis for the prevention and treatment of addictive behaviours. In N. Heather, W.R. Miller \& J.

Greeley (Eds.), Self-Control and the Addictive Behaviours. Australia: Maxwell MacMillan.

Miller, W.R., \& Rollnick, S. (1991). Motivational interviewing: Preparing people to change addictive behavior. New York: Guilford. 
O’Hare, T.M. (1990). Drinking in college: Consumption patterns, problems, sex differences and legal drinking age. Journal of Studies on Alcohol, 51, 536-541.

Perri, M.G., \& Richards, C.S. (1977). An investigation of naturally occurring episodes of self-controlled behaviors. Journal of Counseling Psychology, 24, 178-183.

Robertson, I., Heather, N., Dziadowski, A., Crawford, J., \& Winton, M. (1986). A comparison of minimal versus intensive controlled drinking treatment interventions for problem drinkers. British Journal of Clinical Psychology, 25, 185-194.

Rogers, M.E. (1983). Diffusion of Innovation (3rd Ed.). New York: Free Press.

Saltz, R.,\&Elandt,D. (1986). College student drinking studies 1976-1985. Contemporary Drug Problems, 117-159.

Sanchez-Craig, M., Davila, R., \& Cooper, G. (1996). A self-help approach for high-risk drinking: Effect on and initial assessment. Journal of Consulting and Clinical Psychology, 94, 694-700.

Sanchez-Craig, M., Leigh, G., Spivak, K., \& Lei, H. (1989). Superior outcome of females over males after brief treatment for the reduction of heavy drinking. British Journal of Addiction, 84, 395-404.

Sobell, M.B., Sobell, L.C., Klajner, F., Pavan, D., \& Basian, E. (1986). The reliability of a timeline method for assessing normal drinker college students' recent drinking history: Utility for alcohol research. Addictive Behaviors, 11, 149-161.

Stevens, J. (1992). Applied multivariate statistics for the social sciences. Hillsdale, NJ: Lawrence Erlbaum Associates.

Tabachnick, B.G., \& Fidell, L.S. (1989). Using multivariate statistics (2nd ed.). New York: Harper \& Row.

U.S. Department of Health and Human Services (1991). Healthy People 2000: National health promotion and disease prevention objectives. (DHHS Publication No. PHS90-50212). Washington, DC: U.S. Government Printing Office.

Wechsler, H.,\&Isaac, N. (1992). "Binge” drinkers at Massachusetts Colleges. Journal of the American Medical Association, 267, 2929-2930.

White, R.H.,\&Labouvie, E.W. (1989). Towards the assessment of adolescent problem drinking. Journal of Studies on Alcohol, 50, 30-37. 